\title{
Strong Pressure Effect on the Curie Temperature of Itinerant-Electron Metamagnetic $\mathrm{La}\left(\mathrm{Fe}_{0.88} \mathrm{Si}_{0.12}\right)_{13} \mathrm{H}_{y}$ and $\mathrm{La}_{0.7} \mathrm{Ce}_{0.3}\left(\mathrm{Fe}_{0.88} \mathrm{Si}_{0.12}\right)_{13} \mathrm{H}_{y}$
}

\author{
Shun Fujieda ${ }^{1}$, Asaya Fujita ${ }^{1}$ and Kazuaki Fukamichi ${ }^{2}$ \\ ${ }^{1}$ Department of Materials Science, Graduate School of Engineering, Tohoku University, Sendai 980-8579, Japan \\ ${ }^{2}$ Institute of Multidisciplinary Research for Advanced Materials, Tohoku University, Sendai 980-8577, Japan
}

\begin{abstract}
The initial pressure shift of the Curie temperature $T_{\mathrm{c}}$ for the first-order transition, $\mathrm{d} T_{\mathrm{c}} / \mathrm{d} P$, for $\mathrm{La}\left(\mathrm{Fe}_{0.88} \mathrm{Si}_{0.12}\right)_{13}$ becomes small after hydrogen absorption. In addition, the hydrogen absorption reduces the ratio of the volume change at $T_{\mathrm{c}}$ to the magnetization squared at $T_{\mathrm{c}}$, $\Delta \omega\left(T_{\mathrm{c}}\right) / M\left(T_{\mathrm{c}}\right)_{\mathrm{F}}^{2}$, suggesting the decrease of the magnetoelastic coupling constant $\kappa C_{\mathrm{mv}}$. On the other hand, $\mathrm{d} T_{\mathrm{c}} / \mathrm{d} P$ is enhanced by the partial substitution of $\mathrm{Ce}$ for $\mathrm{La}$ in connection with the change of the band structure. Consequently, $\mathrm{d} T_{\mathrm{c}} / \mathrm{d} P$ of $\mathrm{La}_{0.7} \mathrm{Ce}_{0.3}\left(\mathrm{Fe}_{0.88} \mathrm{Si}_{0.12}\right){ }_{13} \mathrm{H}_{y}$ is larger than that of $\mathrm{La}\left(\mathrm{Fe}_{0.88} \mathrm{Si}_{0.12}\right)_{13} \mathrm{H}_{y}$ in a wide change of $T_{\mathrm{c}}$. [doi:10.2320/matertrans.MBW200822]
\end{abstract}

(Received October 20, 2008; Accepted December 19, 2008; Published February 25, 2009)

Keywords: pressure effect, metamagnetic transition, hydrogen absorption, magnetovolume effect, spin fluctuation

\section{Introduction}

$\mathrm{La}\left(\mathrm{Fe}_{x} \mathrm{Si}_{1-x}\right)_{13}$ compounds with $0.86 \leq x \leq 0.90$ exhibit the thermal-induced first-order transition between the paramagnetic $(\mathrm{P})$ and the ferromagnetic $(\mathrm{F})$ states at the Curie temperature $T_{\mathrm{c}} \cdot{ }^{1)}$ By applying magnetic field, the itinerantelectron metamagnetic (IEM) transition, that is, the firstorder transition to the $\mathrm{F}$ state takes place above $T_{\mathrm{c}} \cdot{ }^{1)} \mathrm{A}$ cubic $\mathrm{NaZn}_{13}$-type structure of the $F m \overline{3} c$ space group is kept after undergoing the thermal-induced first-order transition ${ }^{2,3)}$ and the IEM transition. ${ }^{4)}$ In addition, the unit cell volume in the $\mathrm{F}$ state is larger than that of the $\mathrm{P}$ state because in a large spontaneous volume magnetostriction associated with the local magnetic moment. ${ }^{2-4)}$ Therefore, $T_{\mathrm{c}}$ is significantly decreased by applying hydrostatic pressure. ${ }^{3)}$ The critical temperature $T_{0}$ of the disappearance of the IEM transition also decreases with increasing pressure. ${ }^{5)}$ The pressure effect on $T_{0}$ is smaller than that on $T_{\mathrm{c}}$, and hence the temperature difference, $T_{\mathrm{c}}-T_{0}$, increases with increasing pressure. ${ }^{5)}$ A close interplay between magnetism and volume, namely, the large magnetovolume effects in $\mathrm{La}\left(\mathrm{Fe}_{x} \mathrm{Si}_{1-x}\right)_{13}$ have been explained in terms of band structure and spin fluctuation based on the Landau-Ginzburg model for the IEM transition. ${ }^{3,5-7)}$

The unit cell volume of $\mathrm{La}\left(\mathrm{Fe}_{x} \mathrm{Si}_{1-x}\right)_{13}$ is isotropically expanded, and $T_{\mathrm{c}}$ is increased up to about $330 \mathrm{~K}$ by hydrogen absorption. ${ }^{89}$ The both temperatures of $T_{\mathrm{c}}$ and $T_{0}$ increase, while the value of $T_{0}-T_{\mathrm{c}}$ decreases. ${ }^{10)}$ In contrast, the unit cell volume is decreased by the partial substitution of Ce for $\mathrm{La}$, because the ionic radius of $\mathrm{Ce}$ is smaller than that of $\mathrm{La}$ due to the lanthanide contraction. ${ }^{11,12)}$ In this case, the temperatures of $T_{\mathrm{c}}$ and $T_{0}$ are decreased and the value of $T_{0}-T_{\mathrm{c}}$ is increased. ${ }^{13)}$ Therefore, the volume dependence of $T_{\mathrm{c}}$ and $T_{0}$ for $\mathrm{La}\left(\mathrm{Fe}_{x} \mathrm{Si}_{1-x}\right)_{13} \mathrm{H}_{y}$ and $\mathrm{La}_{1-z} \mathrm{Ce}_{z}\left(\mathrm{Fe}_{x} \mathrm{Si}_{1-x}\right)_{13}$ is qualitatively consistent with that of $\mathrm{La}\left(\mathrm{Fe}_{x} \mathrm{Si}_{1-x}\right)_{13}$ under hydrostatic pressure. However, it has been pointed out that the IEM transition of $\mathrm{La}\left(\mathrm{Fe}_{x} \mathrm{Si}_{1-x}\right)_{13}$ under hydrostatic pressure is different from that of $\mathrm{La}_{1-z} \mathrm{Ce}_{z}\left(\mathrm{Fe}_{x} \mathrm{Si}_{1-x}\right)_{13}$ having a similar value of $T_{\mathrm{c}}{ }^{14,15)}$

In the present paper, to discuss the difference between the influence of the hydrogen absorption and the partial substitution of $\mathrm{Ce}$, the pressure effect on $T_{\mathrm{c}}$ for $\mathrm{La}_{0.7} \mathrm{Ce}_{0.3}\left(\mathrm{Fe}_{0.88} \mathrm{Si}_{0.12}\right)_{13} \mathrm{H}_{y}$ and $\mathrm{La}\left(\mathrm{Fe}_{0.88} \mathrm{Si}_{0.12}\right){ }_{13} \mathrm{H}_{y}$ having a similar value of $T_{\mathrm{c}}$ is investigated.

\section{Experiments}

The $\mathrm{La}_{0.7} \mathrm{Ce}_{0.3}\left(\mathrm{Fe}_{0.88} \mathrm{Si}_{0.12}\right)_{13}$ and $\mathrm{La}\left(\mathrm{Fe}_{0.88} \mathrm{Si}_{0.12}\right)_{13}$ compounds were prepared by arc-melting in an argon gas atmosphere and the heat-treatments were carried out in an evacuated quartz tube. The annealing temperatures of $\mathrm{La}_{0.7} \mathrm{Ce}_{0.3}\left(\mathrm{Fe}_{0.88} \mathrm{Si}_{0.12}\right)_{13}$ and $\mathrm{La}\left(\mathrm{Fe}_{0.88} \mathrm{Si}_{0.12}\right)_{13}$ were 1423 and $1323 \mathrm{~K}$, respectively. The annealing duration was 10 days. The hydrogen absorption was carried out by annealing under a hydrogen gas atmosphere. In order to control the hydrogen content, the annealing temperature and the hydrogen gas pressure were changed. The powder x-ray diffractions were carried out by using $\mathrm{Cu} K \alpha$ radiation. The magnetization was measured with a SQUID magnetometer. The hydrostatic pressure was applied by using a nonmagnetic $\mathrm{Cu}$-Ti clamp cell. The applied pressures were calibrated by measuring the shift of the superconducting transition temperature of $\mathrm{Pb}$.

\section{Results and Discussion}

Figure 1 depicts the thermomagnetization curve in the heating process under a magnetic field of $1 \mathrm{~T}$ for $\mathrm{La}_{0.7} \mathrm{Ce}_{0.3}\left(\mathrm{Fe}_{0.88} \mathrm{Si}_{0.12}\right)_{13} \mathrm{H}_{1.7}$. The Curie temperature $T_{\mathrm{c}}=$ $175 \mathrm{~K}$ of $\mathrm{La}_{0.7} \mathrm{Ce}_{0.3}\left(\mathrm{Fe}_{0.88} \mathrm{Si}_{0.12}\right)_{13}$ is increased up to about $320 \mathrm{~K}$ by hydrogen absorption. Since the magnetization decreases rapidly in the vicinity of $T_{\mathrm{c}}$ with increasing temperature, the thermal-induced first-order transition at $T_{\mathrm{c}}$ remains after hydrogen absorption. The inset represents the powder $x$-ray diffraction patterns of $\mathrm{La}_{0.7} \mathrm{Ce}_{0.3}\left(\mathrm{Fe}_{0.88^{-}}\right.$ $\left.\mathrm{Si}_{0.12}\right)_{13} \mathrm{H}_{1.7}$ and $\mathrm{La}_{0.7} \mathrm{Ce}_{0.3}\left(\mathrm{Fe}_{0.88} \mathrm{Si}_{0.12}\right)_{13}$ at room temperature. The several vertical short bars below the diffraction patterns are the positions of all the possible Bragg reflections from a cubic $\mathrm{NaZn}_{13}$-type structure with the $F m \overline{3} c$ space group. The diffraction patterns of all the specimens are identified as the cubic $\mathrm{NaZn}_{13}$-type structure. The diffraction peaks shift to the lower angle region after hydrogen 


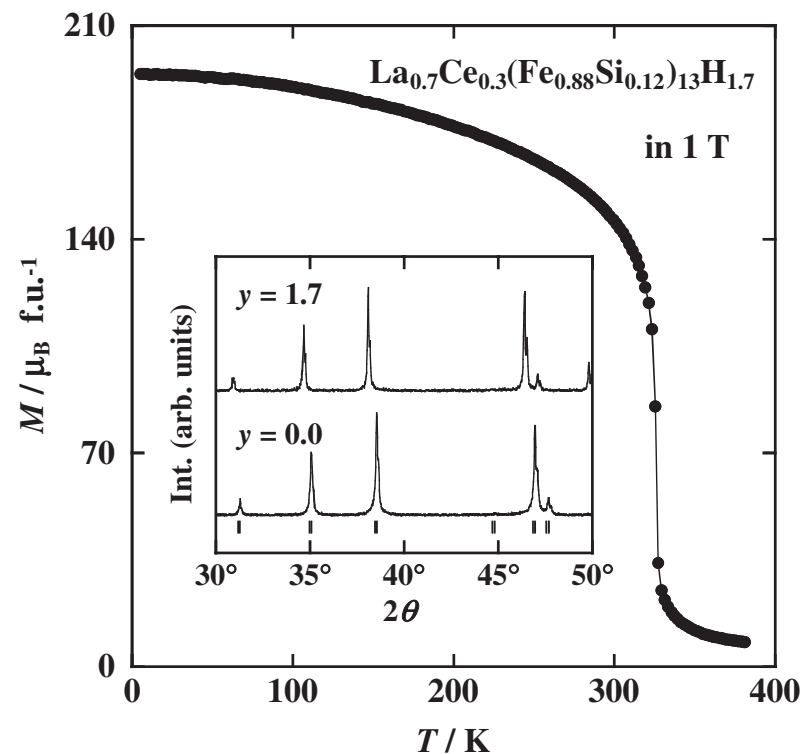

Fig. 1 Thermomagnetization curve in the heating process under a magnetic field of $1 \mathrm{~T}$ for $\mathrm{La}_{0.7} \mathrm{Ce}_{0.3}\left(\mathrm{Fe}_{0.88} \mathrm{Si}_{0.12}\right)_{13} \mathrm{H}_{1.7}$. The inset shows powder $x$-ray diffraction patterns of $\mathrm{La}_{0.7} \mathrm{Ce}_{0.3}\left(\mathrm{Fe}_{0.88} \mathrm{Si}_{0.12}\right)_{13} \mathrm{H}_{y}$ with $y=0.0$ and 1.7. The several vertical short bars below the diffraction patterns stand for the positions of all the possible Bragg reflections from a cubic $\mathrm{NaZn}_{13}$-type structure with the $F m \overline{3} c$ space group.

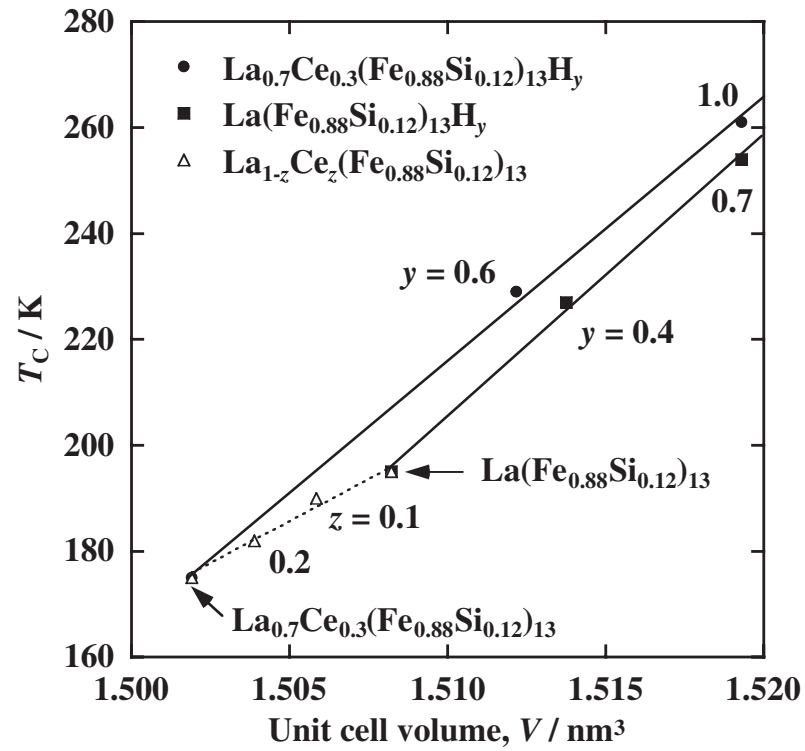

Fig. 2 The Curie temperature $T_{\mathrm{c}}$ as a function of the unit cell volume for $\mathrm{La}_{0.7} \mathrm{Ce}_{0.3}\left(\mathrm{Fe}_{0.88} \mathrm{Si}_{0.12}\right)_{13} \mathrm{H}_{y}$ and $\mathrm{La}\left(\mathrm{Fe}_{0.88} \mathrm{Si}_{0.12}\right)_{13} \mathrm{H}_{y}$, together with that of $\mathrm{La}_{1-z} \mathrm{Ce}_{z}\left(\mathrm{Fe}_{0.88} \mathrm{Si}_{0.12}\right)_{13}$. ${ }^{12)}$

absorption, showing an isotropic expansion of the unit cell volume. Such volume expansion is caused by not only the invasion of hydrogen atom but also the spontaneous volume magnetostriction, because $\mathrm{La}_{0.7} \mathrm{Ce}_{0.3}\left(\mathrm{Fe}_{0.88} \mathrm{Si}_{0.12}\right)_{13} \mathrm{H}_{1.7}$ is in the ferromagnetic state at room temperature.

Figure 2 represents $T_{\mathrm{c}}$ as a function of the unit cell volume at room temperature for $\mathrm{La}_{0.7} \mathrm{Ce}_{0.3}\left(\mathrm{Fe}_{0.88} \mathrm{Si}_{0.12}\right)_{13} \mathrm{H}_{y}$ and $\mathrm{La}\left(\mathrm{Fe}_{0.88} \mathrm{Si}_{0.12}\right)_{13} \mathrm{H}_{y}$, together with that of $\mathrm{La}_{1-z} \mathrm{Ce}_{z}\left(\mathrm{Fe}_{0.88^{-}}\right.$ $\left.\mathrm{Si}_{0.12}\right)_{13}{ }^{12)}$ To discuss the relation between the unit cell volume and $T_{\mathrm{c}}$ without the contribution from the large spontaneous volume magnetostriction, the data on the speci-

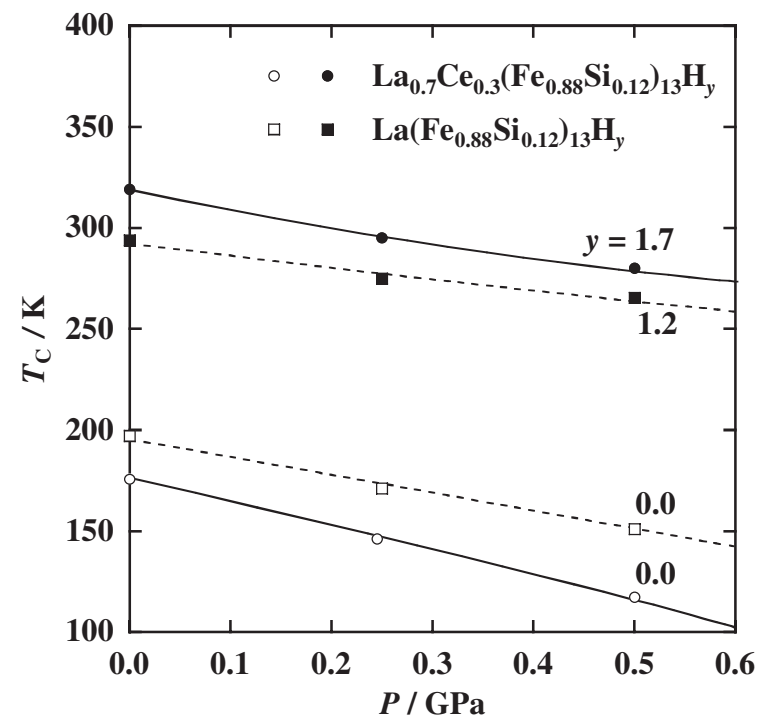

Fig. 3 Pressure shift of the Curie temperature $T_{\mathrm{c}}$ for $\mathrm{La}_{0.7} \mathrm{Ce}_{0.3^{-}}$ $\left(\mathrm{Fe}_{0.88} \mathrm{Si}_{0.12}\right)_{13} \mathrm{H}_{1.7}, \mathrm{La}_{0.7} \mathrm{Ce}_{0.3}\left(\mathrm{Fe}_{0.88} \mathrm{Si}_{0.12}\right)_{13}, \mathrm{La}\left(\mathrm{Fe}_{0.88} \mathrm{Si}_{0.12}\right)_{13} \mathrm{H}_{1.2}$ and $\mathrm{La}\left(\mathrm{Fe}_{0.88} \mathrm{Si}_{0.12}\right)_{13} \cdot{ }^{3)}$

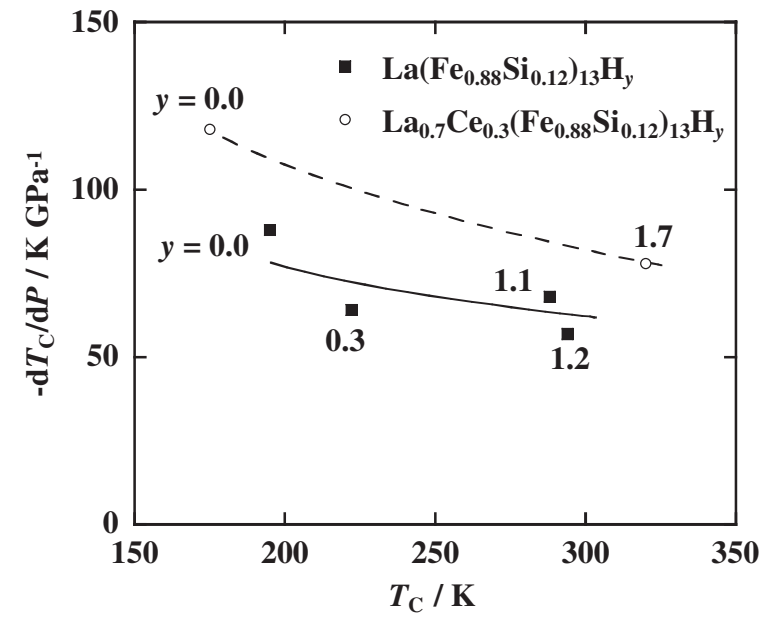

Fig. 4 Relationship between the Curie temperature $T_{\mathrm{c}}$ and the initial pressure shift $\mathrm{d} T_{\mathrm{c}} / \mathrm{d} P$ for $\mathrm{La}_{0.7} \mathrm{Ce}_{0.3}\left(\mathrm{Fe}_{0.88} \mathrm{Si}_{0.12}\right)_{13} \mathrm{H}_{y}$ and $\mathrm{La}\left(\mathrm{Fe}_{0.88} \mathrm{Si}_{0.12}\right){ }_{13} \mathrm{H}_{y}$.

men with $T_{\mathrm{c}}<273 \mathrm{~K}$ are plotted. The value of $T_{\mathrm{c}}$ increases with increasing $y$ and decreases with increasing $z$. The slope of $\mathrm{La}_{0.7} \mathrm{Ce}_{0.3}\left(\mathrm{Fe}_{0.88} \mathrm{Si}_{0.12}\right)_{13} \mathrm{H}_{y}$ is quite similar to that of $\mathrm{La}\left(\mathrm{Fe}_{0.88} \mathrm{Si}_{0.12}\right){ }_{13} \mathrm{H}_{y}$. However, $T_{\mathrm{c}}$ of the former is slightly higher than that of the latter at the same volume. In addition the volume dependence of $T_{\mathrm{c}}$ for the two compound systems mentioned above is stronger than that of $\mathrm{La}_{1-z} \mathrm{Ce}_{z}\left(\mathrm{Fe}_{0.88^{-}}\right.$ $\left.\mathrm{Si}_{0.12}\right)_{13}$.

Figure 3 depicts the pressure shift of $T_{\mathrm{c}}$ for $\mathrm{La}_{0.7} \mathrm{Ce}_{0.3}\left(\mathrm{Fe}_{0.88} \mathrm{Si}_{0.12}\right)_{13} \mathrm{H}_{1.7}$ and $\mathrm{La}_{0.7} \mathrm{Ce}_{0.3}\left(\mathrm{Fe}_{0.88} \mathrm{Si}_{0.12}\right)_{13}$. For comparison, the data of $\mathrm{La}\left(\mathrm{Fe}_{0.88} \mathrm{Si}_{0.12}\right)_{13} \mathrm{H}_{1.2}$ and $\mathrm{La}\left(\mathrm{Fe}_{0.88} \mathrm{Si}_{0.12}\right)_{13}{ }^{3)}$ are also plotted in the same figure. Shown in Fig. 4 is the relationship between $T_{\mathrm{c}}$ and $\mathrm{d} T_{\mathrm{c}} / \mathrm{d} P$ for $\mathrm{La}_{0.7} \mathrm{Ce}_{0.3}\left(\mathrm{Fe}_{0.88} \mathrm{Si}_{0.12}\right)_{13} \mathrm{H}_{y}$ and $\mathrm{La}\left(\mathrm{Fe}_{0.88} \mathrm{Si}_{0.12}\right)_{13} \mathrm{H}_{y}$. The value of $\mathrm{d} T_{\mathrm{c}} / \mathrm{d} P$ was estimated from the initial pressure shift of $T_{\mathrm{c}}$ shown in Fig. 3. The pressure shift of $T_{\mathrm{c}}$ for $\mathrm{La}\left(\mathrm{Fe}_{0.88} \mathrm{Si}_{0.12}\right)_{13}$ is increased by the partial substitution of $\mathrm{Ce}$, whereas it is decreased by hydrogen absorption. 


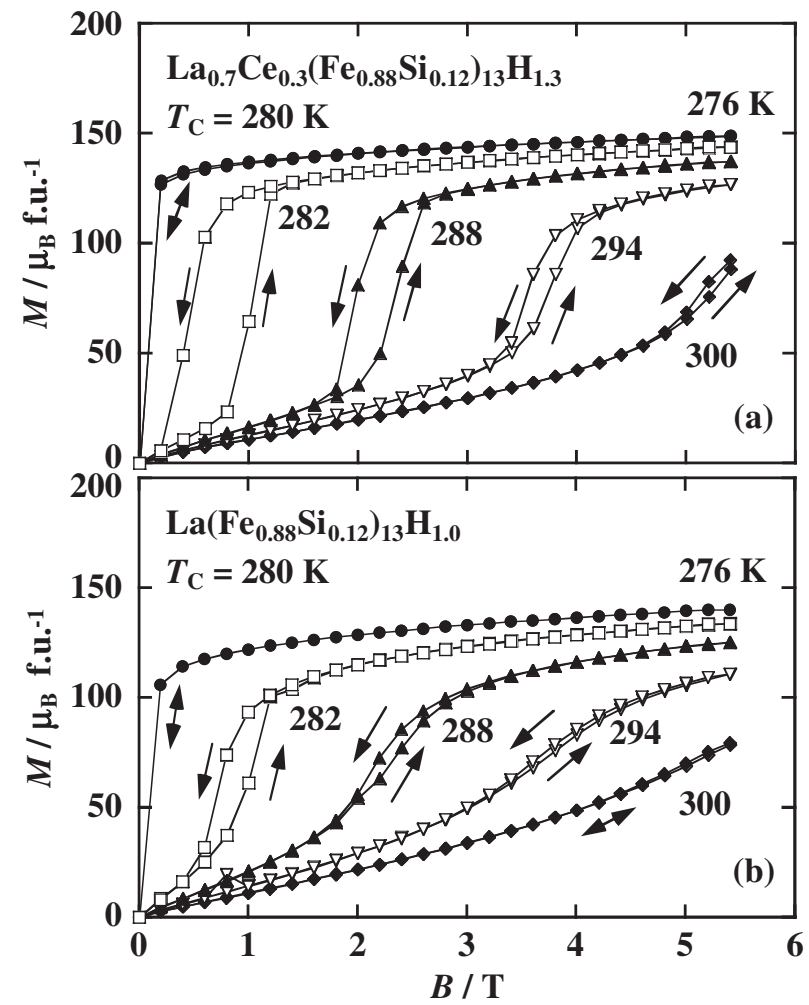

Fig. 5 Magnetization curves of (a) $\mathrm{La}_{0.7} \mathrm{Ce}_{0.3}\left(\mathrm{Fe}_{0.88} \mathrm{Si}_{0.12}\right)_{13} \mathrm{H}_{1.3}$ and (b) $\mathrm{La}\left(\mathrm{Fe}_{0.88} \mathrm{Si}_{0.12}\right){ }_{13} \mathrm{H}_{1.0}$ in the vicinity of the Curie temperature $T_{\mathrm{c}}$. The increasing and decreasing processes of applied magnetic fields are indicated by the arrows.

Similarly, the pressure shift of $T_{\mathrm{c}}$ for $\mathrm{La}_{0.7} \mathrm{Ce}_{0.3}\left(\mathrm{Fe}_{0.88}\right.$ $\left.\mathrm{Si}_{0.12}\right)_{13}$ becomes small after hydrogen absorption. It should be noted that the pressure shift of $T_{\mathrm{c}}$ for $\mathrm{La}_{0.7} \mathrm{Ce}_{0.3}\left(\mathrm{Fe}_{0.88}\right.$ $\left.\mathrm{Si}_{0.12}\right)_{13} \mathrm{H}_{1.7}$ is larger than that for $\mathrm{La}\left(\mathrm{Fe}_{0.88} \mathrm{Si}_{0.12}\right)_{13} \mathrm{H}_{1.2}$, though $T_{\mathrm{c}}$ of the former is higher than that of the latter, showing that the enhancement of $\mathrm{d} T_{\mathrm{c}} / \mathrm{d} P$ caused by the partial substitution of Ce remains after hydrogen absorption. Accordingly, $\mathrm{d} T_{\mathrm{c}} / \mathrm{d} P$ for $\mathrm{La}_{0.7} \mathrm{Ce}_{0.3}\left(\mathrm{Fe}_{0.88} \mathrm{Si}_{0.12}\right)_{13} \mathrm{H}_{y}$ is larger than that for $\mathrm{La}\left(\mathrm{Fe}_{0.88} \mathrm{Si}_{0.12}\right)_{13} \mathrm{H}_{y}$ in a wide change of $T_{\mathrm{c}}$.

The magnetization curves of (a) $\mathrm{La}_{0.7} \mathrm{Ce}_{0.3}\left(\mathrm{Fe}_{0.88}\right.$ $\left.\mathrm{Si}_{0.12}\right)_{13} \mathrm{H}_{1.3}$ and (b) $\mathrm{La}\left(\mathrm{Fe}_{0.88} \mathrm{Si}_{0.12}\right)_{13} \mathrm{H}_{1.0}$ are shown in Fig. 5. The value of $T_{\mathrm{c}}$ for $\mathrm{La}_{0.7} \mathrm{Ce}_{0.3}\left(\mathrm{Fe}_{0.88} \mathrm{Si}_{0.12}\right)_{13} \mathrm{H}_{1.3}$ is about $280 \mathrm{~K}$, being the same as that for $\mathrm{La}\left(\mathrm{Fe}_{0.88} \mathrm{Si}_{0.12}\right)_{13} \mathrm{H}_{1.0}$. The increasing and decreasing processes of applied magnetic fields are indicated by the arrows. A characteristic S-shape magnetization curve with hysteresis is observed above $T_{\mathrm{c}}$ because of the itinerant-electron metamagnetic (IEM) transition. The hysteresis in the magnetization curve of $\mathrm{La}_{0.7} \mathrm{Ce}_{0.3}\left(\mathrm{Fe}_{0.88} \mathrm{Si}_{0.12}\right)_{13} \mathrm{H}_{1.3}$ appears at higher temperatures, indicating that the critical temperature $T_{0}$ of the disappearance of the IEM transition is much higher than that of $\mathrm{La}\left(\mathrm{Fe}_{0.88} \mathrm{Si}_{0.12}\right)_{13} \mathrm{H}_{1.0}$. Such results make it clearer that the influence of the partial substitution of Ce cannot be explained by the volume contraction only.

The magnetovolume effects in itinerant-electron metamagnets have been discussed in terms of the Landau-type expansion of magnetic free energy. ${ }^{16)}$ In the theory, the magnetic free energy is given by the following expression by taking the effects of spin fluctuations, the magnetoelastic energy and the elastic energy into account. ${ }^{16)}$
$F(M)$

$$
=\frac{1}{2}\left\{\tilde{a}(T)+2 \kappa C_{\mathrm{mv}} P\right\} M^{2}+\frac{1}{4} \tilde{b}(T) M^{4}+\frac{1}{6} \tilde{c}(T) M^{6},
$$

with

$$
\begin{aligned}
& \tilde{a}(T)=\tilde{a}(0)+\left\{\frac{5}{3} \tilde{b}(0)+\frac{4}{3} \kappa C_{\mathrm{mv}}^{2}\right\} \xi(T)^{2}+\frac{35}{9} \tilde{c}(0) \xi(T)^{4} \\
& \tilde{b}(T)=\tilde{b}(0)+\frac{14}{3} \tilde{c}(0) \xi(T)^{2}, \quad \tilde{c}(T)=\tilde{c}(0)
\end{aligned}
$$

where $\xi^{2}$ is the means-square amplitude of thermal spin fluctuations. The values of $\tilde{a}(0), \tilde{b}(0)$ and $\tilde{c}(0)$ are the Landau coefficients related to the $3 d$ band structure, and $\kappa C_{\mathrm{mv}}$ is the magnetoelastic coupling constant. When $\tilde{a}(0)>0$, $\tilde{b}(0)<0, \tilde{c}(0)>0$ and $5 / 28-\eta<\tilde{a}(0) \tilde{c}(0) / \tilde{b}(0)^{2}<3 / 16$ $\left(\eta=2 \kappa C_{\mathrm{mv}}^{2} / 7|\tilde{b}(0)|\right)$, the magnetic free energy has two minima at $M=0$ in the paramagnetic state and at a finite value of $M$ in the ferromagnetic state, resulting in the thermal-induced first-order transition at $T_{\mathrm{c}}$ and the IEM transition above $T_{\mathrm{c}}{ }^{16)}$ Under these conditions, the pressure shift of $\xi^{2}$ at $T_{\mathrm{c}}$ for the first-order transition is given by ${ }^{16)}$

$$
\begin{aligned}
& \frac{d \xi\left(T_{\mathrm{c}}\right)^{2}}{d P} \\
& \quad=-\frac{6}{\sqrt{7}} \frac{\kappa C_{\mathrm{mv}}}{|\tilde{b}(0)|}\left[\frac{\tilde{a}(0) \tilde{c}(0)}{\tilde{b}(0)^{2}}-\frac{5}{28}+\eta+28 \eta^{2}\right]^{-1 / 2} .
\end{aligned}
$$

According to the theoretical discussion, $\xi^{2}$ increases in proportion to $T^{2}$ at low temperatures, and to $T$ at high temperatures. ${ }^{17)}$ It has been pointed out that the critical field $B_{\text {c }}$ of the IEM transition for $\mathrm{La}\left(\mathrm{Fe}_{0.88} \mathrm{Si}_{0.12}\right)_{13}$ increases in line with $T^{1.2}$ above $T_{\mathrm{c}}=195 \mathrm{~K}{ }^{10)}$ This result means that $\xi^{2}$ for $\mathrm{La}\left(\mathrm{Fe}_{0.88} \mathrm{Si}_{0.12}\right)_{13}$ depends on $T^{1.2}$ in the vicinity of $195 \mathrm{~K}$, because $B_{\mathrm{c}}$ has a proportional relation with $\xi^{2}{ }^{17)}$ Thus $\mathrm{d} \xi\left(T_{\mathrm{c}}\right)^{2} / \mathrm{d} P$ of the present compound system can be approximately given by $\mathrm{d} T_{\mathrm{c}} / \mathrm{d} P$. By adapting the thermodynamic relation: $\partial F / \partial M=B$ to eq. (1), it reveals that the volume change causes not only the decrease of $T_{\mathrm{c}}$ but also the change of magnetization curve. However, it has been pointed out that the IEM transition of $\mathrm{La}_{0.7} \mathrm{Ce}_{0.3}\left(\mathrm{Fe}_{0.86} \mathrm{Si}_{0.14}\right)_{13}$ with the same $T_{\mathrm{c}}$ is clearer than that of $\mathrm{La}\left(\mathrm{Fe}_{0.86} \mathrm{Si}_{0.14}\right)_{13}$ under the hydrostatic pressure $P=0.25 \mathrm{GPa},{ }^{14)}$ resulting in the changes of $\tilde{a}(0), \tilde{b}(0)$ and $\tilde{c}(0)$. Therefore, the enhancement of $\mathrm{d} T_{\mathrm{c}} / \mathrm{d} P$ due to the partial substitution of $\mathrm{Ce}$ is attributed to the change of the band structure as can be understood from eq. (3).

The value of $\mathrm{d} T_{\mathrm{c}} / \mathrm{d} P$ is also affected by the value of $\kappa C_{\mathrm{mv}}$ as seen from the same equation. Based on the theoretical discussion of itinerant-electron magnetism by taking the effect of spin fluctuations into account, the magnetic contribution to the thermal dependence of the volume, namely, the spontaneous volume magnetostriction $\omega(T)$ is given by ${ }^{18)}$

$$
\omega(T)=\kappa C_{\mathrm{mv}}\left\{M(T)^{2}+\xi(T)^{2}\right\} .
$$

Thus, the volume change $\Delta \omega$ at $T_{\mathrm{c}}$ for the first-order transition is expressed as ${ }^{18)}$

$$
\Delta \omega\left(T_{\mathrm{c}}\right)=\kappa C_{\mathrm{mv}}\left\{M\left(T_{\mathrm{c}}\right)_{\mathrm{F}}^{2}-\xi\left(T_{\mathrm{c}}\right)_{\mathrm{P}}^{2}\right\},
$$

where $M\left(T_{\mathrm{c}}\right)_{\mathrm{F}}$ is $M$ at $T_{\mathrm{c}}$ in the F state and $\xi\left(T_{\mathrm{c}}\right)_{\mathrm{P}}^{2}$ is $\xi^{2}$ at $T_{\mathrm{c}}$ in the $\mathrm{P}$ state. Summarized in Table 1 are $\Delta \omega\left(T_{\mathrm{c}}\right), M\left(T_{\mathrm{c}}\right)_{\mathrm{F}}$ and $\Delta \omega\left(T_{\mathrm{c}}\right) / M\left(T_{\mathrm{c}}\right)_{\mathrm{F}}{ }^{2}$ of $\mathrm{La}\left(\mathrm{Fe}_{0.88} \mathrm{Si}_{0.12}\right)_{13}$ and $\mathrm{La}\left(\mathrm{Fe}_{0.88^{-}}\right.$ $\left.\mathrm{Si}_{0.12}\right)_{13} \mathrm{H}_{1.6}$. The values of $\Delta \omega\left(T_{\mathrm{c}}\right)$ and $M\left(T_{\mathrm{c}}\right)_{\mathrm{F}}{ }^{2}$ were 
Table 1 The volume change $\Delta \omega\left(T_{\mathrm{c}}\right)$ at the Curie temperature $T_{\mathrm{c}}$ and magnetization $M\left(T_{\mathrm{c}}\right)$ at $T_{\mathrm{c}}$, together with the ratio $\Delta \omega\left(T_{\mathrm{c}}\right) / M\left(T_{\mathrm{c}}\right)^{2}$ of $\mathrm{La}\left(\mathrm{Fe}_{0.88} \mathrm{Si}_{0.12}\right)_{13}$ and $\mathrm{La}\left(\mathrm{Fe}_{0.88} \mathrm{Si}_{0.12}\right)_{13} \mathrm{H}_{1.6}$.

\begin{tabular}{lccc}
\hline & $\Delta \omega\left(T_{\mathrm{c}}\right)(\%)$ & $M\left(T_{\mathrm{c}}\right) / \mu_{\mathrm{B}}$ & $\Delta \omega\left(T_{\mathrm{c}}\right) / M\left(T_{\mathrm{c}}\right)^{2} / \mu_{\mathrm{B}}^{-2}$ \\
\hline $\mathrm{La}\left(\mathrm{Fe}_{0.88} \mathrm{Si}_{0.12}\right)_{13}$ & 0.82 & 1.0 & 0.82 \\
$\mathrm{La}\left(\mathrm{Fe}_{0.88} \mathrm{Si}_{0.12}\right)_{13} \mathrm{H}_{1.6}$ & 0.54 & 0.9 & 0.67 \\
\hline
\end{tabular}

evaluated from x-ray diffraction patterns ${ }^{3)}$ and Mössbauer spectra, ${ }^{3,19)}$ respectively. As seen from Table $1, \Delta \omega\left(T_{\mathrm{c}}\right)$ of $\mathrm{La}\left(\mathrm{Fe}_{0.88} \mathrm{Si}_{0.12}\right)_{13} \mathrm{H}_{1.6}$ is about $65 \%$ of that before hydrogen absorption. On the other hand, $M\left(T_{\mathrm{c}}\right)_{\mathrm{F}}^{2}$ for the former is about $80 \%$ of that for the latter. As a result, $\Delta \omega\left(T_{\mathrm{c}}\right) / M\left(T_{\mathrm{c}}\right)_{\mathrm{F}}{ }^{2}$ of $\mathrm{La}\left(\mathrm{Fe}_{0.88} \mathrm{Si}_{0.12}\right)_{13} \mathrm{H}_{1.6}$ corresponds to about $80 \%$ of that before hydrogen absorption. It is clear from eq. (5) that such behavior can be explained by the decrease of $\kappa C_{\mathrm{mv}}$ and/ or the increase of $\xi\left(T_{\mathrm{c}}\right)_{\mathrm{P}}{ }^{2}$ due to the hydrogen absorption, although the values of $\kappa C_{\mathrm{mv}}$ and $\xi\left(T_{\mathrm{c}}\right)_{\mathrm{P}}^{2}$ are not evaluated qualitatively at the present stage. It should be noted that the decrease of $\mathrm{d} T_{\mathrm{c}} / \mathrm{d} P$ for $\mathrm{La}\left(\mathrm{Fe}_{0.88} \mathrm{Si}_{0.12}\right)_{13} \mathrm{H}_{1.2}$ is about $70 \%$ as shown in Fig. 4. This value is close to that of $\Delta \omega\left(T_{\mathrm{c}}\right) / M\left(T_{\mathrm{c}}\right)_{\mathrm{F}}^{2}$, suggesting that the decrease of $\mathrm{d} T_{\mathrm{c}} / \mathrm{d} P$ for $\mathrm{La}\left(\mathrm{Fe}_{0.88} \mathrm{Si}_{0.12}\right)_{13} \mathrm{H}_{y}$ is mainly attributed to the decrease of $\kappa C_{\mathrm{mv}}$ rather than the increase of $\xi\left(T_{\mathrm{c}}\right)_{\mathrm{P}}{ }^{2}$. Such influence of hydrogen absorption differs from that of the partial substitution of $\mathrm{Ce}$. Consequently, it stands to reason that the influence of the partial substitution of $\mathrm{Ce}$ on $\mathrm{d} T_{\mathrm{c}} / \mathrm{d} P$ remains after hydrogen absorption, resulting in the stronger pressure effect on $T_{\mathrm{c}}$ for $\mathrm{La}_{0.7} \mathrm{Ce}_{0.3}\left(\mathrm{Fe}_{0.88} \mathrm{Si}_{0.12}\right)_{13} \mathrm{H}_{y}$.

\section{Conclusion}

The initial pressure shift of the Curie temperature $T_{\mathrm{c}}$, namely, $\mathrm{d} T_{\mathrm{c}} / \mathrm{d} P$, for $\mathrm{La}\left(\mathrm{Fe}_{0.88} \mathrm{Si}_{0.12}\right)_{13}$ becomes small after hydrogen absorption. In addition, the hydrogen absorption causes the reduction of the ratio of the volume change at $T_{\mathrm{c}}$ to the magnetization squared at $T_{\mathrm{c}}, \Delta \omega\left(T_{\mathrm{c}}\right) / M\left(T_{\mathrm{c}}\right)_{\mathrm{F}}{ }^{2}$. Therefore, it is suggested that the decrease of $\mathrm{d} T_{\mathrm{c}} / \mathrm{d} P$ due to the hydrogen absorption is mainly attributed to the decrease of the magnetoelastic coupling constant $\kappa C_{\mathrm{mv}}$. On the other hand, $\mathrm{d} T_{\mathrm{c}} / \mathrm{d} P$ is enhanced by the partial substitution of Ce for $\mathrm{La}$ in connection with the change of the band structure. As a result, the enhancement of $\mathrm{d} T_{\mathrm{c}} / \mathrm{d} P$ due to the partial substitution of Ce remains after hydrogen absorption. Consequently, the pressure effect on $T_{\mathrm{c}}$ of $\mathrm{La}_{0.7} \mathrm{Ce}_{0.3}\left(\mathrm{Fe}_{0.88^{-}}\right.$ $\left.\mathrm{Si}_{0.12}\right)_{13} \mathrm{H}_{y}$ is stronger than that of $\mathrm{La}\left(\mathrm{Fe}_{0.88} \mathrm{Si}_{0.12}\right)_{13} \mathrm{H}_{y}$ in a wide change of $T_{\mathrm{c}}$.

\section{Acknowledgement}

This work was supported by the Elements Science and Technology Project of MEXT.

\section{REFERENCES}

1) A. Fujita, Y. Akamatsu and K. Fukamichi: J. Appl. Phys. 85 (1999) 4756-4758.

2) K. Fukamichi and A. Fujita: J. Mater. Sci. Technol. 16 (2000) 167-171.

3) A. Fujita, S. Fujieda, K. Fukamichi, H. Mitamura and T. Goto: Phys. Rev. B 65 (2002) 014410, 1-6.

4) A. Fujita, K. Fukamichi, K. Koyama and K. Watanabe: J. Appl. Phys. 95 (2004) 6687-6689.

5) A. Fujita, K. Fukamichi, M. Yamada and T. Goto: J. Appl. Phys. 93 (2003) 7263-7265.

6) A. Fujita, K. Fukamichi, M. Yamada and T. Goto: Phys. Rev. B 73 (2006) 104420, 1-5.

7) A. Fujita, K. Fukamichi, J.-T. Wang and Y. Kawazoe: Phys. Rev. B 68 (2003) 104431, 1-6.

8) S. Fujieda, A. Fujita, K. Fukamichi, Y. Yamazaki and Y. Iijima: Appl. Phys. Lett. 79 (2001) 653-655.

9) S. Fujieda, A. Fujita, K. Fukamichi, Y. Yamaguchi and K. Ohoyama: J. Phys. Soc. Jpn. 77 (2008) 074722, 1-8.

10) A. Fujita, S. Fujieda, Y. Hasegawa and K. Fukamichi: Phys. Rev. B 67 (2003) 104416, 1-12.

11) S. Fujieda, A. Fujita and K. Fukamichi: Mater. Trans. 45 (2004) 32283231.

12) S. Fujieda, A. Fujita, K. Fukamichi, N. Hirano and S. Nagaya: J. Alloy. Compd. 408-412 (2006) 1165-1168.

13) S. Fujieda, A. Fujita and K. Fukamichi: J. Magn. Magn. Mater. in press.

14) A. Fujita and K. Fukamichi: First Int. Conf. on Magnetic Refrigeration at Room Temperature, ed. by P. W. Egolf (Int. Institute of Refrigeration, Paris, 2005) pp. 201-209.

15) A. Fujita, S. Fujieda and K. Fukamichi: J. Appl. Phys. 99 (2006) 08K910, 1-3.

16) H. Yamada, K. Fukamichi and T. Goto: Phys. Rev. B 65 (2002) 024413, 1-6.

17) H. Yamada: Phys. Rev. B 47 (1993) 11211-11219.

18) H. Yamada and K. Terao: J. Phys.: Condens. Matter. 6 (1994) 1080510809.

19) A. Fujita, S. Fujieda and K. Fukamichi: J. Magn. Magn. Mater. in press. 